\title{
YOUTH CORRECTION: PRINCIPLES OF DIAGNOSIS, TREATMENT, AND PROGNOSIS
}

\author{
WILLIAM HEALY*
}

The stark fact of the extent of recidivism proves that our prevailing methods of handling youthful offenders fail in great measure to protect society from ill-doers. In a large percentage of cases their careers go on for years and years with continued outbreaks of antisocial conduct.

Our philosophy of dealing with youthful criminality lacks substantial foundations because it does not take into account the issues presented by the personality, the background life, and the developed behavior tendencies of the offender. Save in the best efforts of thoroughly competent probation and parole officers, and perhaps in very rare correctional institutions, our techniques of treatment-if we dare to call it treatment-are woefully unadapted to the task of turning a young criminal into a lawabiding citizen.

The model Youth Correction Authority Act contemplates providing measures which look to the substitution, in the case of the youthful offender, of scientific methods of diagnosis, treatment and prognosis for the inadequate techniques so generally prevailing today. It is the purpose of this article to outline and appraise the proper implementation of a Youth Correction Authority-or any like body-if legislation along the lines of the Model Act were adopted. But, first, let us consider our characteristic ways of dealing with youthful offenders.

Unforgettable is "Toronto Jim" and his story of treatment under the law, told one quiet suburban Sunday afternoon some thirty years ago. Brought to the conference by a manufacturer who had successfully engaged him in honest work for a couple of years, he, at forty-eight, looked more like a bank president than the notorious bank burglar and safe blower that he had been. His good friend had known all along about his penal record and had become much interested in the question why an obviously intelligent human being, in spite of many legally inflicted punishments, had engaged in such a career. Could we together formulate any answer; if

- A.B., 1899, Harvard University; M.D., I900, Rush Medical College, University of Chicago; postgraduate study, Ig06-7, Vienna, Berlin, and London. Director, Judge Baker Guidance Center, Boston, since rgr7; lecturer, Harvard University and Boston University. Director, Juvenile Psychopathic Institute, Chicago, I909-I7; professor and research associate, Institute of Human Relations, Yale University, I929-33. Author of numerous works on psychology and delinquency, including The INDividual Desineuent (1915), Personality in Formation and Action (1937); (with A. F. Bronner) Delineuents and Criminals-Their Maring and Unmaring (1926), New Light on Delinquency and its Treatment (i936), and Treatment and What Happened Afterward (r940); (with B. S. Alper) Criminal. Youth and the Borstar. System (r94I). Contributor of numerous articles to periodicals. 
so would it not add to the knowledge of how criminal careers are engendered? The erstwhile Toronto Jim, known as such throughout the Middle West, was willing to tell his story and, for the most part, told it rather impersonally. Notes were taken and the story can be retold.

Beginnings were in a companionship affair when he was little more than $a^{\prime}$ boy, an amateur breaking and entering for which he received a prison sentence-the first of a dozen or more typical incarcerations in different states. No rancor was expressed about the sentences, about prison regulations, work or food, but the hundreds and hundreds of empty hours-these from the first were irksome, these are what lead to the undoing of jailed men. What do prisoners find to think about in idle hours? Quick and savage came the answer as Jim for the moment became an inmate again, "What the hell do you suppose we think about? Our mistakes, of course; why didn't we do a better job! There's plenty of rotten thoughts running through our minds, of course, and attempts to have rotten talk and practices, but for me and the pals I made the big question was how to make a better break next time; how to gain more skill, use better tools, make a better get-away, leave no identifying traces. In a year I'd easily have a couple of thousand hours to think about all that."

As the story went on it came out plainly that from the first "stretch" in the reformatory nobody made any attempt really to know Jim or to train him for any suitable outside occupation. He was always let alone-that was the treatment-since he was canny enough to obey all the rules in order to get out as quickly as possible. For nearly all the guards and higher officials that he had ever seen he expressed great contempt-"political appointees; ignorance and fear lead them to use only hardboiled methods; many are shut-eye sentries if there is anything in it for them."

Jim's professional acquaintanceship gradually enlarged after he came out for the first time and found it hard to get work in his home town because of his record. Former prison mates elsewhere were always glad to take up with him-he quickly learned from some of these. Later he himself did some teaching of a few brighter ones whom he had approached in prison and who were willing to meet him when they came out. Parole officers never played any active part in his life; sometimes he had to make formal reports and "that was that." When he was "in the money," what practically amounted to blackmail had to be paid to others of his craft and, he said, in some cities to the police.

Why had he never served a term longer than three years? Because he worked so cleverly that it was troublesome for the police to produce sufficient evidence to convict. Yet there was always the chance that a judge or jury could be convinced, so it was common practice for the states attorney to "make a deal" with him, and although guilty of a major offense he would plead guilty to a smaller one which he did not commit, and receive a comparatively light sentence. That was another phase of his treatment under the law.

Three times he had tried to break away from the game and start in a small business way for himself, but after being visited by those of his ilk who had ferreted 
out his whereabouts, or after being "investigated" by the police, each time he had to give it up. Until he was employed under the protection of our friend, the manufacturer, Jim maintained that since his first reformatory experience he never had a ghost of a show to live and work honestly and decently.

Jim summarized his views: "The trouble is that society does not do either enough to us or for us."

The only response to the first of these alternatives surely is that we have grown far beyond the age of attempting to insure the protection of society by extreme punitive devices. Our humanitarian sympathies, our sense of social justice, our feelings of responsibility for the existence of conditions which breed criminality, all nowadays come into play. Hence we cannot permit ourselves to inflict very long prison terms, say of thirty or twenty years, upon hundreds and thousands of young fellows annually, though they be repeated offenders, in order to keep them out of circulation during the life period when there is considerable likelihood that they will again offend. Then from a hard-headed standpoint we may envisage the bewildering increase of prison populations if such commitments were made, and the social burden of the decrepitude of men in middle life released from such long preventive sentences. No, hit-or-miss, when a prison sentence is prescribed we resort to shorter terms as punishment and take a chance on whether or not society in the long run is thereby protected.

But Jim failed to recognize that his second alternative does not preclude employment of the first. The problem in the case of an offender is not "either . . . or. . . ." As in medical and surgical practice the procedure of doing something to a person may rationally be made part of a whole process of doing something for him. The analogies between social pathology as represented by criminality and medical pathology are very suggestive. The interests of society are deeply involved in curative measures for both. Segregation for a period may be and often is the first requisite step in therapy.

And now it is fair to ask whether these thirty odd years since Jim's story was told show marked advances in dealing with young offenders. To be sure, for various reasons quite other than our methods of dealing with individual offenders, we have very few professionals of Toronto Jim's stripe; hence this fact is beside the point. Taking our country by-and-large, and excepting, as we stated earlier, the best types of probation and parole services and while acknowledging some improvements in the physical aspects and in the recreational and educational facilities of prison life, we venture to doubt any great betterment of really essential methods of treatment or in results. The figures for recidivism are too large for us to believe to the contrary.

We have recently, opportunely for this paper, interviewed half-a-dozen young men fresh from serving sentences, fellows known to us, all of them, to be trustworthy in statement. They did not come in to make complaints; none of them spoke of unfair treatment; they came, rather, to report as to a former friend and to seek suggestions 
about their future. Accounts of their institutional life were obtained only in response to inquiries.

One account, by an immensely vigorous intense young man, of nearly a year in a large House of Correction shows conditions, well confirmed by others, to be on the one hand absurdly comfortable for those who have some funds and can sink readily to a low level, but, on the other hand, through idleness and other factors, utterly debasing in human relationships, even between guards and inmates.

A youth of twenty, with assets distinctly above the average, during his two years in a reformatory found the life, with the long hours of cell confinement common to such institutions, exceedingly "soft." Moreover, no one appeared to have the slightest personal interest in him. He was never spoken to about his family life or companionships, matters of considerable import in his case, or about his ideals, ambitions or vocational aptitudes. He received no training of value to him. Having a good record in the institution he was transferred to a place of more freedom within walls. There the only one who talked to him at all about his future was a fellow inmate, a pimp who offered him a job transporting prostitutes from place to place.

Another fine-appearing youth had just served a term at one of our most noted reformatories for some hold-ups with a couple of desperate criminals. He was given psychological tests, classified and put at an occupation, printing, for which as a very active, extremely adventurous and sea-loving boy he was totally unfitted. His good qualities were recognized and reported, though no inquiry was made into his earlier life, nor were his natural drives and urges recognized. However, with good sense he maintained a perfect record, settled himself down to do very well at printing, only to find on release what is well known, namely, that in recent years there has been a surplusage of school-trained young printers, and lately no chance whatever for such employment. In the reformatory there must have been mechanical training and schooling that might well have fitted him for advancement in the sea life that the boy had begun and still craved. As a matter of fact he was glad that nobody could find a printing job for him, and, joining the merchant marine, he has enlisted on some of the most hazardous trips of these war days.

A boy who had sustained a remarkable series of head accidents resulting in a complete change of personality voluntarily reported to us the very day he was released from the reformatory. Nobody earlier had known what to do with him; he had been to clinics and hospitals and several times to a correctional school. $\mathrm{He}$ wanted himself to know now what to do about his behavior tendencies. The year and more that he spent at the last institution he spoke of as the dullest of experiences; he was entirely left alone because he followed regulations. One could think of the possibilities of that year-opportunities only made possible by prolonged segregationmodern neurological studies, long-time exploration of the inner conflicts which we know he had about his behavior, observation of occupational conditions under which he might be most stable. No estimate was made of possible medical or surgical treatment, no advice was given him or his parents before discharge; and except for any 
steering that might be given by an overworked parole officer upon release he was still adrift.

The upshot of all this is clear. Our dealing with young criminals under the law and under legislative provisions is almost barren of the common-sense principles of diagnosis, treatment and prognosis. To say that sound scientific attitudes are lacking in this task which is supposed to aim at the protection of society is to speak of something far beyond any mark that we have so far set for ourselves. Indeed, science, so responsible for other improvements in social living, has never had a foothold in this field. Here in treatment methods we are in the age of old wives' medicine-we prescribe varying dosages of traditional unproved remedies, namely, penal segregation, for symptoms only, totally neglecting what might be known about causes and prognosis.

\section{Diagnosis}

Exactly for the purpose of estimating in a given case the possibilities-and, indeed, also the impossibilities-of obtaining good results from various forms of training and treatment, well-rounded diagnostic case studies of the individual are requisite. This means very much more than the common routine physical examination and psychological testing.

In the first place it is necessary to know what manner of person the young offender is; what his physical and mental status is, what he is from the standpoint of personality and character development-all in terms of both assets and liabilities. Next, the interests of society are deeply involved in the important question of what the individual's needs are that can be supplied by any phases of a sensibly constructed plan of training and treatment. A fundamental consideration for the diagnostic study of youthful offenders is the cormmon-sense fact that either there must have been abnormal urges-true in only a very small percentage of cases-or, as in the vast majority of instances, there must have been thwarting of satisfactions of quite normal needs which, had they been satisfied, would have prevented the growth of the tendency to unlawful behavior. For the diagnosis of these needs and their distortions we are often compelled to investigate etiological factors, at least as far as proximate or immediate factors of motivation of the particular offender's criminality is concerned. The individual who has adequate satisfactions in other than criminal activities does not engage in criminality.

This matter of the diagnosis of the offender's needs which have not received satisfactions represents a vastly important salient in the warfare on crime. Of course this is well recognized by all practical-minded workers for the prevention of delinquency, but equally the knowledge of specific needs which, case by case, may vary greatly is indispensable for all well-directed treatment of the youthful criminal who is in the hands of the law. Many published studies by ourselves and others deal with the multiplicity of factors that in given cases tend to produce delinquency and crime; hence there is no call to enumerate them here. It is sufficient to say that they range from peculiarities in the physical, mental and personality make-up of the individual, 
or circumstances in his social and particularly his family environment, or matters of early conditioning, to deep-lying emotional rẹactions to his life experiences.

In our research studies for the Yale Institute of Human Relations ${ }^{1}$ where we compared delinquent and non-delinquent siblings, even twins, living together under the same family conditions, the most striking findings concerning differences were those related to the emotional life, to the satisfaction of needs. The non-delinquent, even under very unfavorable environmental conditions had found needful satisfactions in activities other than unlawful behavior. The delinquent through his make-up or conditionings had needs that varied so from those of his sibling that under a largely similar life situation they were not fulfilled; or the delinquent, though not so dissimilar, was the one of the two who had been beset in his development by certain specific inimical conditions and experienccs frustrating to his needs even within the family circle. The delinquent behavior had meaningfulness for the offender; it consciously or unconsciously seemed to promise satisfactions; it was one way out of the often vaguely felt states of dissatisfaction. Thus we were able to generalize about diagnosis as an absolutely necessary prerequisite for the treatment process: above everything there must be knowledge and understanding of the implications of the offender's unsatisfied needs, just in order to aid him to develop the power to obtain adequate lawful satisfactions.

In thinking about diagnosis, particularly from the standpoint of directly causative factors, some of the impracticabilities of treatment often have to be considered. However much certain personal handicaps, for example, have figured in the past in the causation picture, sometimes it may be clear that they are not susceptible to any kind of treatment that can be offered-these may be matters pertaining to the physical or mental constitutional equipment of the individual, they may be the result of disease or accident. Or a bad family or other social situation may not be remediable. Occasionally the diagnosis of a grave form of personality abnormality may be made, abnormality that does not yield to treatment; and so on through quite a long list of factors.

But always, even where irremediable factors are found, the diagnosis must be concerned with the latent possibilities of the case, with discoverable assets that the individual may possess through which he may profit by measures of reconstruction. What are his capacities for benefiting by physical, educational, or social training? Or has he emotional problems that can be solved by psychotherapy? Or can his needs be met, as in many a probation case, by a change of environment?

Thus efficient diagnosis in all cases must not be limited to the offender's disabilities or to his inimical earlier life experiences, but must include his potentialities for reformation. It is just the same in medical diagnosis: the individual is found to have some particular ailment, perhaps in some organ, through having led an unhealthy life; but careful diagnostic notes are taken of the strength of his other organs

\footnotetext{
${ }^{2}$ Reported in Healy and Bronner, New Light on Delinquency and its Treatmant (1936).
} 
or of his ability to begin to live healthfully, signs that point to the possibility of cure if indicated measures of treatment for the specific ailment are undertaken.

Let no one believe that any such diagnosis, which has as its intensely practical aim the proper prescription of a training and treatment process, is very easily or speedily arrived at. The mere giving of the usual physical examination and psychological tests falls very short of what is essential. To be sure, the classification system common in our reformatories is based on these short studies of the offender, together perhaps with a little knowledge of his attitudes and habits. But the ordinary reformatory is run on preconceived notions of what can practicably be done with prisonersjust a few types of work are offered, the kinds of vocational training are exceedingly limited, recreational facilities are very narrow, physical training is scanty, the encouragement of special interests for which the offender may have ability is almost nil. Thus classification is for the purpose of fitting the individual into a narrowly constructed regime and having it work smoothly. The man is to fit into the institution's requirements; mighty little thought is given to fitting the services of the personnel or regime to the offender's requirements for reconstruction.

In discussing adequate diagnoses of young offenders for a much better oriented process of reformatory treatment we need not theorize about what can be done; we can learn a great deal from what has been found entirely practicable under the Borstal System in England. There, after an offender $x 6$ to 23 years of age has been adjudged to present a problem serious enough to warrant his commitment to the thorough-going training methods of the Borstal institutions he is forthwith sent to an observation center which functions for the whole system. A study of the individual is begun which includes many phases of his case. Besides the investigation of his previous life, which usually has already been made, he undergoes careful physical and mental examinations, and treatment for physical ailments and defects is given. In addition he is observed with regard to his personal habits, his interests and capabilities, and his reactions to segregation, discipline, work and companionship.

Though merely designated a period of observation, this is truly a diagnostic procedure undertaken for the purpose of placing the offender in the type of training from which he will probably profit most. A case record is compiled which is studied by the governor of the particular Borstal which would seem by its special methods and life to offer most chances for reconstructive upbuilding. The governor has an interview with "the lad," but no final decision is made until an allocating conference is held. This is attended by the various officers who have studied the boy, and his case is discussed, for and against any specific type of treatment. Finally the offender is brought in and the decision explained to him. Some leeway is allowed for his expression of opinion, for example, whether he would like hardy out-door life, or would be willing to live up to the regulations of an open Borstal, or desires most the special vocational training given in some walled institution.

This diagnostic period, though it takes about a month, has proven its worth because accuracy of judgment at this time makes it very rarely necessary to transfer to 
another type of institution. Moreover, by its very rationality and fairness it makes a deep impression upon the offender, and this is part and parcel of the treatment process. But it must not be supposed that this is the end of all diagnosis of the individual's needs. In the institution to which he is sent it may be discovered that he has certain special needs-for some particular kind of physical upbuilding, for the development of some interests or capabilities that have come to light, and very often for the unburdening of emotional conflicts about himself or his family. These findings partake of the nature of a continuing diagnostic study. ${ }^{2}$

Applicable to the possible discovery of factors related to the behavior tendencies of young offenders, a considerable number of diagnostic methods have been more recently evolved. These new tools, as they may be called, can be utilized for the ascertainment of previously little understood physical and personality functionings which deviated from the healthy or socially desirable norm. Our own clinical experiences show that in some cases of offenders the results of these newer diagnostic methods throw light upon indirect and even direct causes of delinquent and criminal behavior. For example, we may cite the use of the electroencephalogram to detect even latent epileptic malfunctioning of the brain, which in some instances is closely associated with antisocial behavior. Or we know how careful investigation of the functionings of the endocrine system, the glands of internal secretion, may unearth some fact bearing upon the individual's tendency to misbehave. Without overemphasizing just one of the possible findings in this latter field of diagnostic study, the significance of the modern laboratory analysis of the male and female hormones, the androgen and estrogen content of the body fluids, in homosexuals may be mentioned.

From the standpoint of personality diagnosis there have been developed within a few years new techniques by which the individual, through so-called projective methods, apparently largely reveals his personality deviations in test situations. To know the offender in this way might well serve in adapting forms of training and treatment for him. This is certainly a provocative subject for diagnostic research.

Then we should utilize very up-to-date means for diagnosing cases of abnormal personality - the abnormally unstable-egocentric individuals, frequently termed psychopathic personalities, and the constitutionally inadequate types, both of which after correctional sentences so frequently continue in long careers of crime. A mass of information has been accumulated concerning the cost to society of these and of some other abnormal personality types, but little cognizance of the diagnostic facts has been taken in terms of what is requisite in many such cases, namely, prolonged segregation or colonization. Neglect of modern knowledge of these abnormal personalities, the cases of which are explainable often by earlier disease or injury of brain cells or by original defects in brain organization, is, we noted, one of the weakest points in the Borstal System.

\footnotetext{
sor a much more detailed account of all this, see Healy and Alper, Criminal Youth and tute Borstax System (Commonwealth Fund, r941).
} 
Also scientific workers in this field have an ever-growing realization that it is very important to diagnose the feeling life of the offender, to know if there have been emotional conflicts that have led to outbreaks of criminal conduct. Sometimes these inner disturbances are well concealed and it takes skill to uncover their presence. But discovery of the fact is not enough; knowledge of the nature and source of the troublesome states of mind is essential. Clues may be obtained through acquaintance with the earlier life experiences of the individual, as well as through diagnostic interviews. Reconstructive treatment in not a few instances is entirely dependent for success upon diagnostic discovery of these elements within the personal life. It was extremely interesting to note the ways in which the highly intelligent personnel of the Borstals had educated themselves to find indications of such emotional disturbances on the part of their inmates before arranging opportunities for shrewdly conceived therapeutic interviews.

The Youth Correction Authority Act was deliberately planned to emphasize the common sense of diagnosis before treatment, and to provide ample opportunity for developing resources for scientific.diagnosis. Also implicit in the wording of certain sections of the $\mathrm{Act}^{3}$ (explicit in an earlier draft) is appreciation of the value of continuing diagnostic research.

\section{Data for Diagnosis}

This is no place for even a much abbreviated schedule for medical, psychiatric, psychological and sociological diagnoses. Specialists in any or all of these disciplines who study offenders should, of course, be well trained in the fundamentals of their science and keep abreast of everything proven of worth in their field. All that we propose to do here is to give broad hints as to where exceptional values lie in developing the less usually collected types of data for diagnosis, upon which appropriate training and treatment should be based.

Physical Diagnosis. What does the offender's type of body build signify; what does it call for during the training and treatment period? What assets does it offer for vocational training or for the development of recreational skills and hobbies that may stand the individual in good stead during his institutional life or after release? This also applies, we have found, to reconstructive efforts with young offenders on probation.

What can be ascertained about the offender's special dietary faults and requirements for sound health and energy-vitamin requirements, etc.? Laziness and loafing are sometimes dependent upon these matters. And there are definite diagnostic possibilities, particularly of the endocrine equipment and of other biochemical functionings bearing upon the energy output, plus or minus, which in turn may be related to conduct manifestations. This is found to be true in general clinical practice; why not among offenders where marked tendencies to explosive behavior, irritability, restlessness or undue physical and mental lethargy frequently exist?

\footnotetext{
' Youth Correction Authority Act (A. L. I., Official Draft, 1940) \$\$8, 28, 3 I.
} 
And the problems correlated with excess of physical development in general and with constitutional excess of energy, since these sometimes play a causative part in the more adventurous types of crime, should be taken account of during the training period. Sexual overdevelopment or overfunctioning can easily be understood, also, as something to be considered in the treatment process.

Physical inferiorities, deformities, or defects, sometimes even those hidden from the public eye, are particularly to be noted in relation to the individual's feelings about them. Consciously or unconsciously, as we clinicians frequently find, they may cause deeply fixed emotional conflicts. It is, however, the psychiatrist's job to make this latter part of the diagnosis.

Nor is it going too far to suggest that a skilled eye specialist who is familiar with recent research in his field may diagnose conditions that have prevented earlier school and vocational satisfactions and in consequence have had a bearing upon the production of a delinquent career. Such conditions if unknown and not remedied may stand in the way of the individual's success on probation or in reformatory training.

Psychological Diagnosis. The grading of an offender according to an intelligence quotient or an age level of mental ability may have no little importance for his adjustment to a training program, but much may be overlooked diagnostically if the psychological examination is limited to such a rating. Besides discovery of exceptional general intelligence or of mental defect, for the practical purposes of laying out an educational and vocational program for the individual, either on probation or in an institution, the determination of special abilities is essential. Through the exercise and development of such capabilities come some of life's greatest satisfactions. The diagnosis of motor dexterity and mechanical skills is especially important because these do not correlate highly with general intelligence. For estimating special fitness for various types of trades and occupations there are nowadays many tests and the use of them has value because when a youth assigned to some kind of training finds himself inefficient at it, naturally his morale is lowered-and exactly the reverse is true.

Then from what we have observed in some very successful reformatory programs abroad, we are convinced that there is a great deal to be gained for both the temporary and permanent upbuilding of the individual's better interests and character through the discovery that he has some special aptitude for artistic performance or appreciation. This may easily lead to growth of new wholesome interests or to vigorous renewal of those formerly cherished. It might well be the duty of the psychologist to study the individual from the standpoint of how his ambitions and interests can be awakened through realization that he has some special ability for achievement, say, in the plastic or graphic arts-drawing, painting, modeling, carving $\multimap$ or in music or in the drama.

To be challenging and satisfying to the individual, any of these forms of selfexpression demands some degree of native talent which can be diagnosed.

The modern psychologist is interested in a wide variety of other tests, some of 
which may have value for dealing with the offender. There are tests for educational achievement, for mathematical aptitude, apperceptive abilities, mental control, for powers of visual representation, and so on. Then, too, there is the present-day interest in the diagnosis of personality qualities and organization by means of a number of tests, but the application of these to any part of the training and treatment program is largely uncertain, though certainly open to what may prove to be valuable research.

The psychologist should also have a sharp eye for educational lacks which rest on inabilities that sometimes can at least be partially remedied during a training period. One could think of a defect for working with numbers which, after diagnosis of its nature and causes, could possibly be helped by ingenious educational devices. And, even more particularly, there is the matter of reading disability with which psychologists and educators have been much concerned in recent years. This represents in some instances a difficulty which makes the individual appear to be mentally defective and, of course, rules him out of many a job. The bearing of this disability upon school and vocational dissatisfaction and hence upon the establishment of criminalistic behavior we have definitely witnessed. A great need of some offenders can be met through accurate diagnosis of the nature of the difficulty followed by remedial education. Their future conduct may in no inconsiderable degree depend upon what aid they may have received in overcoming their reading disability.

Psychiatric Diagnosis. The psychiatrist dealing with offenders after court adjudication is only rarely concerned with the problem of insanity, legal irresponsibility, although an occasional probationer or institutional inmate may present mild or temporary psychotic symptoms that approach the borderline of insanity. Then the diagnosis, as always with such patients, should include analysis of the whole personality picture and what is especially askew that may be susceptible to treatment. The same is true when the offender presents neurotic symptoms or is definitely a neurotic personality. The problem in all these cases is one of mental hygiene, and treatment to prevent further disaster cannot properly be oriented without an accurate diagnosis of the underlying trouble in each individual case.

The diagnosis of abnormal personality, previously mentioned, unfortunately up to the present cannot be related to any known possibility of treatment. And yet the diagnosis is important in order to prevent probation officers, institutional authorities, parole boards and their officers from being misled by the frequent high intelligence quotient, the plausibility, the poise, and the promises of such personalities, and from putting forth great effort, as is often the case, in attempting to accomplish the impossible.

Undoubtedly from the standpoint of aiding the largest number of offenders to end their criminalistic tendencies the very greatest diagnostic task is to discover those who have developed emotional attitudes that bar the way to reformation. Among the most important of such attitudes, of which the offender in some instances may not be consciously aware, are those of skepticism, recklessness, grudge, revenge, despair, insecurity, or regression to childish levels. A helpful diagnosis does not stop with the 
bare fact, but takes account of the emotional frustrations, the dynamic issues that have given rise to the unfortunate attitudes.

Developmental History. For the diagnosis of various physical and mental deviations, personality peculiarities and neurotic symptoms, an accurate and detailed history of the development of the individual is vital. This should begin with anything that may have affected the individual deleteriously before birth. Pur case records of criminal careers show clear-cut instances of such effects upon the unborn child. Then inquiry into the whole later life history should be made for diseases and injuries that, in particular, may have damaged the brain. Clinicians are very much alive to these factors nowadays because of the accumulation of knowledge concerning the after-effects not only of head injuries at birth and later, but also of certain infectious diseases, such as encephalitis, particularly the form commonly known as sleeping sickness, and chorea, any of which sometimes bring about important degenerative changes in those portions of the brain that control behavior tendencies. And similar defect in inhibitory control of conduct results when brain pathology of a chronic nature follows, as it occasionally does, in the wake of respiratory diseases severe enough to cause states of anoxemia-the brain cells being deprived of oxygen for a period and to a degree sufficient for degenerative processes to set in. This very incomplete statement of certain pathologies serves at least to indicate that the criminality of some youthful offenders may be related to damage of brain tissue.

The whole account of the individual's physical and mental growth; his physical and mental habits; his urges, drives, and ability to control his impulses from an early age; his emotional attitudes in general, and particularly his reactions to frustrations; his interests and ambitions and personality development at various age periods should be available, if possible, for diagnostic interpretation of any deviation from the norm.

Social History. Out of a good social history grow many diagnostic understandings of why the offender has been an offender. It is the story of human interrelationships, the boy and his immediate relatives, their circular response to each other, the boy and the influences of his companionships. With regard to the family it may be the story of an absent, an indifferent, a drinking, abusive, or even a hating and hated father. Or the mother may have been over-dominant, or over-protective, or unloving; worse than that, she may have been a mother to be ashamed of. The story may include illegitimacy or adoption, with obvious conflictual feelings about the fact. There are a hundred and one variations possible, but the emotional reactions engendered in the youngster by his life experience within the family circle form one of the most dynamic factors in the evolution of delinquent trends. To know exactly what these social factors, inside or outside the home, have been, is to make a diagnosis that in many cases is the sole foundation upon which reconstructive personal influences, whether or not they are termed psychotherapy, can be effective.

Educational History. It goes without saying that diagnosis must take account of the opportunities, or lack of them, for education, including religious education. But the quantity and types of instruction offered are of little import compared to the 
individual's response to some teacher or clergyman. Some account of this may be obtained from the family or other sources, but frequently the true facts only come out through the offender being given friendly encouragement to tell his own story. Then again will be discovered the influence of human relationships in shaping a career.

Criminal History. The particular forms of delinquency and criminality that have been engaged in, their frequency or infrequency, and their occurrence at special age periods have much bearing upon diagnosis of what has been going wrong with the individual-a fact that is much worth knowing in planning effective training and treatment.

The whole diagnostic picture can only be completed by considering the possible significance of many items, particularly those indicated above. Only by filling in the background as well as the foreground with ascertained, valid, concrete factual material can we hope to state diagnostically about the offender: (a) what, in terms of causal relations to his criminality, he is in and of himself, in his inner mental life, and in his reactions to his life experiences, and then (b) from this, what his equipment and needs suggest for a program of training and treatment that may offer the . greatest likelihood of preventing further criminality.

\section{Training and Treatment}

Fortunately we are able to speak about a training and treatment program for offenders of the age group covered by the Youth Correction Authority Act, not from a theoretical standpoint, but rather from what we know has been in effective operation, at least until war-times, in various correctional systems. From these we can learn practical possibilities. Besides our knowledge of the camp program for offenders in California and the regime of the unusual reformatory institution at Annandale, New Jersey, we may draw upon our observations of the correctional commune system in Russia, the Danish scheme for the rehabilitation of offenders, and especially upon our prolonged studies of the Borstal System in England. Aside from this we know of little that was being done in other countries applicable to the development of a more effective reformatory program in this country. In Russia and in Denmark we saw some few features of correctional treatment that in modified form we could profitably utilize. In England by the trial and error method there has been gradually evolved a highly intelligent and largely successful pattern of training and treatment for youthful offenders which in many respects we might well copy.

Indispensable for the success of such a system is a specially qualified personnel, including everybody, from the superintendent to the disciplinary officers and guards, who by virtue of his position necessarily influences the offenders. Herein lies the cardinal difference between the equipment of our reformatories and that of the Borstal System. ${ }^{4}$ With our enterprising manhood, so frequently seeking satisfying fields of endeavor, must we in the United States necessarily be so far behind?

The qualities of the personnel of the Borstal System, their devotion and initiative, are discussed in the book already mentioned, supra note 2. Also many details of the varied forms of training are described. 
Since youthful offenders, case by case, present the diversity of requirements for upbuilding that diagnostic considerations show, the next step toward common-sense treatment must then be taken by providing a variety of training and treatment resources. Requisite in any one state is the establishment of a number of relatively small units with the several types of regime and training adapted to the differing needs of offenders. Our congregate reformatories which in so many ways offer obstructions to the individualization of treatment are hopeless for carrying out scientifically oriented systems of training. Though improvements in method may seem to imply great expenditures for new institutions, expensive buildings are far from necessary. Institutions of maximum security there must be for a certain class of cases, but part of already existing facilities could be used for this purpose.

For establishing the other units one sees no reason why the English scheme cannot be followed, having the offenders themselves play a great part in constructing the plant. Indeed the pioneering spirit which is such a part of our national tradition might be so skilfully invoked that many youths under sentence would regard participation in the development of a new project as a great adventure. Not only this, but the many details of planning and building and organizing a largely self-sustaining unit would serve many educational aims and constitute part of a program for physical and vocational training. Officials with imagination could educationally relate the different kinds of projects at different centers to our civic and national life and thus engender the feeling for responsible citizenship. The camps for offenders in California have already gone part way in showing what can be done and the response of youths to the hardiest kind of constructional labor in some of the Borstals, while other aspects of training are also part of the daily regime, proves even more what the possibilities are.

Implied in what we have already said about diagnosis is the necessity for a properly staffed and equipped observation center where the cases of offenders may be studied for a period sufficient to make a first determination of what types of training they require.

Here, before we deal with the more specific measures of soundly organized methods of training, the general principles which must underlie them should be emphasized. First, it is imperative to eliminate the softness of life which, so far as physical and mental activity is concerned, characterizes our reformatories and prisons. The debilitating effects of long unoccupied hours in cells are surely apparent, but it is not generally understood that the kind of comfortableness afforded by such a regime is not so unwelcome to many offenders that they take pains to avoid being returned to it. Indeed our own and other studies of young criminals make it clear that some, more or less consciously, seek renewal of such a period of freedom from self-directive responsibility and from the necessity for making a livelihood. They have learned that it is possible to adjust themselves to bodily comforts on a low level and to the pleasures derivable from idle phantasies. Such offenders by no means abhor this state of dependency-the prison life resembles that afforded by the spoiling 
mother, the necessaries of life are given and only a minimum demand is made for anything in return, even for self-development.

The vigorous, arduous day of a Borstal, in marked contrast, approaches the ideal, with its carefully planned full activities in work, education, physical exercise and recreation. The youth speedily recognizes the value of such a program for his selfdevelopment and in most cases comes to enjoy it. The short-time experience of the camps in California indicates a similar response, and probably Annandale can tell the same story.

The other fundamental principles of treatment must be concerned with definitive physical improvement of the offender, with furthering his vocational possibilities, with development of his powers of self-direction, with the strengthening of his personal and civic morale. Every human being has need for recognition and encouragement, especially while he is beginning to put forth efforts to aid himself-this must be incorporated in the principles of treatment, and even more the positive values of dignified but friendly understanding contacts between the offender and some one officially over him to whom he may look up as embodying characteristics of what a man should be.

\section{Specific Mrasures for Training and Treatment}

The following memoranda represent only high-lighting of some suggestive considerations for the reformative training and treatment process.

Physical Training. There is always much to be gained by the systematic physical training of young offenders. In weighing the values of setting-up exercises, drill, active participation in sports, etc., account may well be taken of the human needs thus met. Among other things there may be growth in feelings of adequacy and newly felt capacity for self-control arising from the ability to manage adeptly one's own body.

We observed, for example, with great interest the very evident pride and satisfaction displayed by a group who gave for us an impromptu exhibition of gymnastics at Portland, one of the Borstals for difficult older offenders. We happened at the noon rest hour to be passing the gymnasium and a number of young men nearby were asked to show us the results of the physical training they receive. The exercises they went through on the bars, the horse and in tumbling, and their form in doing them would have done credit to a Bohemian gymnastic club. After noting the general attitudes of the inmates one could but agree with the governor of that Borstal in feeling that insistence on good posture and encouragement of bodily grace and skill may be a great factor in developing the self-respect which is the first step toward reformation. At that institution with $35^{\circ}$ inmates there were no less than three physical training instructors who gave full time to the athletic program and to remedial exercises. And at Feltham, to which those with physical and mental defects were sent, there were also three physical education experts. Then we may add that we were much impressed by the programs for physical upbuilding in the remarkable hostels for youthful offenders in Copenhagen. 
Vocational Training. In institutional life, as elsewhere, undoubtedly the best principles upon which to base vocational training are the following: to utilize the best aptitudes of the individual; to arouse interest in the job at hand; to produce results of which the worker may be proud; to make or construct something of such real value that it is utilized; to train for vocations in which the individual can find employment.

Any American visitor to Russian communes for youthful offenders can easily realize that their methods, extremely valuable though they may be in the Russian scene, cannot be realized in this country. For one point, they develop such skilled workmen that, for instance, in one commune visited, high-class musical instruments-violins and balalaikas-are manufactured to be sold on the open market. The workers are paid the same wages as on the outside. On account of this and the peculiar freedom of living conditions, no wonder that a large percentage of those who earlier were offenders choose to remain permanently and to marry or bring wives and children to the commune after the terms of their sentences have expired.

The Danish training scheme also is utterly inapplicable here. There the young erstwhile offenders are legally apprenticed in a wide variety of trades and crafts, and for the most part while serving under the conditions of commitment to institutions or hostels go out to their daily work.

At a former visit to one of the Borstals we were greatly impressed by the quality of the products of the machine shop-propeller shafts and other carefully gauged machine parts for the Navy. Later we saw metal articles manufactured for the post office department, and also, fabricated in the foundries from raw steel and iron, all the metal construction materials for one of their modern structures. The really fine buildings at Lowdham Grange have been entirely constructed, even to the joinery, plumbing, electrical fitting, and tasteful interior decorations, by the inmates under the direction of competent artisan instructors. Everywhere, in the drafting rooms and shops and even in the training of chefs, was apparent the educative skill of the teaching staff-and also the obviously vigorous interest on the part of the inmates.

What stands in the way of obtaining these results here? The disapproval of the labor unions? In England the unions have come to see the general social value of training Borstal inmates in building construction, metal working, etc., and as competence is gained it is recognized by granting a definite status as a worker in the trade.

Academic Training. The possibilities of schooling in the evening, after a day's work, are so well accepted that they hardly need mention. In Denmark, where good primary education is almost universal, the evening sessions were concerned with technical instruction, such as would intrigue many of our young men. Points about the Borstal schooling are its recognition that the subject matter to be profitably handled must arouse interest, and that studies in history, geography, and government can be turned in the direction of teaching citizenship values-all this, of course, demanding ingenuity on the part of the instructor. 
Training in Appreciations and Self-expression. The use of talents in creative effort leads to a kind of satisfaction that nothing else gives. If creative ability is lacking, development of appreciations in the field of the arts may mean much. Music, drawing and painting, modeling, artistic work in handicraft, the drama-all offer more than mere recreational values; they are outlets for self-expression and foster aesthetic sensibilities that are often underestimated in character building. Much emphasis was placed on such pursuits in the Russian communes for young offenders-talent was discovered and encouraged, even for professional careers. The museum with a rather notable collection of paintings, etchings and other art work by inmates was proudly shown. So, too, at the Borstals; the leisure periods and "hobby hours" were often given to creative work which found a place in the decoration of buildings and in exhibits. Volunteer teachers from the outside community gave their professional services for training in music and the graphic and plastic arts to those who signified a desire for them. It was felt that the direct and indirect influence of this kind of training should not be overlooked in a world where appreciation of the beautiful is often absent, and especially for a group that often has had little or no first-hand experience with artistic effort.

Personal Infuences. As we have already indicated, vastly important fundamentals in training and treatment are the influences which emanate from those who are in charge of the young offender or who attempt in any way to offer treatment for him. The mechanized regime of our congregate reformatories apparently largely demands the offender's depersonalization-all must be treated alike; both the inmates and the staff look with suspicion upon the introduction of any friendly or even professional therapeutic endeavors. And yet in nearly all instances it is the psyche, the ideational and emotional life of the offender, that stands most in need of treatment-treatment that can only be given through intimate understandings of ideas and feelings. More than anything else it is the individual's personal attitudes toward life that need to be re-formed.

In the Russian communes these reformative influences are expected to become active through the offender's rubbing up against his fellows who, under the new opportunities afforded them, have decided to go straight. In Denmark the effect of frequent contacts with an understanding and wholesome leader is well recognized, and to that end the leaders are most carefully chosen.

In the Borstals the whole training process and particularly the system of private interviews partakes of the nature of psychotherapy, though not designated as such. It requires a very capable personnel to maintain this mental hygiene point of view, but through self-education, and studying the case histories of their charges, and learning by experience and by staff conferences, at which the prime needs of individual inmates are discussed, this high standard of treatment is maintained. The heads of the Borstals gave much credit to certain members of their staffs-a Catholic priest, a house master, a shop director, a civil engineer in charge of squads at workfor their genius in accomplishing much through personal relationships established; 
and it was evident that the heads themselves devoted a good deal of time to making such contacts.

In this country the clinical experience of modernly trained psychiatrists proves, not only the need for treatment of the emotional life of offenders, but also what good results can obtain from such therapy. However, the regime of our correctional institutions is forbidding for this approach to the problems of offenders. The sooner this is altered, the better will be the prospects for less recidivism.

Discipline. In the training of offenders infliction of punishments for nonconformity and infraction of rules is everywhere sometimes necessary. As one learns about the various forms of punishment that are given in this country and abroad, one notes anything but unanimity of opinion about what forms are most effective, what grades of punishment should be inflicted for different types of offenses, what responses are encountered in special personality types. Even if these were known as pertaining to the individualization of treatment, we should still have left some questions about another factor, namely, the effect of the personality attitudes of the official who ordered the punishment. In particular, was he clearly fair and just? One must think of the offender's attitude towards society after he is released, will he be embittered and become antisocial as the result of the particular punishment, or will he have received training thereby that will make him more likely to abide by the rules of society?

Then there is the psychiatric approach to this problem of punishment. Is the guilty one an abnormal personality, subject to behavior impulses which he cannot control; or has he had an emotional flare-up which practically amounts to a temporary psychosis? Or, as a much more subtle question which occasionally should be answered, is the offender the victim of a masochistic attitude: does he seek punishment as an answer to an inner sense of guilt?

Treatment of Abnormal Personalities. Now we come to one of the most difficult problems to be met in dealing with offenders, a problem not solved at all, even by the Borstal System. Indeed through not having psychiatric diagnostic studies of their offenders the problem is not faced there. Undoubtedly, as elsewhere, the abnormal personalities account for a very definite percentage of the failures. The fact is that after a diagnosis is carefully arrived at, certainly of one type, namely, the too loosely termed psychopathic personalities-better designated as those who are abnormally unstable egocentric personalities-everyone is at a loss to know what to do about treatment. The records of recidivism of such individuals show that society would best protect itself by their prolonged segregation. Experiments are under way in some federal correctional institutions in this country to see whether under very special forms of treatment, such individuals can gain enough insight to comport themselves better in the prison regime. But how, after such treatment, they will behave when again free cannot as yet be predicted.

About another type, the constitutionally inferior or inadequate, the problem is to build them up as much as possible in bodily strength and character. Probably the 
Borstals do considerable for this class of cases. However, there then comes the question of adjusting them on parole to conditions which afford them enough satisfactions on a simple level so that they will not be so easily tempted to obtain what they want by law breaking.

Treatment on Probation and Parole. Some parts of what we have said above apply to treatment of the offender on probation and parole-certainly the points that were made about treatment for physical defects and ailments, the utilization of vocational aptitudes, the development of methods for increasing personal and citizenship morale, the needs for recognition and encouragement, and the immense value of constructive personal influences.

The diagnostic and treatment measures undertaken by the Citizenship Training School, connected with the Boston Juvenile Court, which boys on probation have to attend after school hours, is a unique attempt to supplant the usual formal occasional reporting of probationers by an intelligently varied program, including psychiatric interviews, aimed at building up the individual and stimulating him to acquire better standards and interests. But could such a therapeutic endeavor be successfully organized for groups of older youthful offenders? We rather doubt its feasibility for them.

The scheme of using hostels for probationers and parolees who would better live away from an old deleterious environment is a matter open to argument. This scheme has been thought so well of in English practice that the Criminal Justice Bill which, except for the oncoming of the war would probably have been passed by Parliament, made budgetary provisions for its extension. There are experienced workers with offenders who say it will never do in our country-the risk of placing a group of offenders together is too great. That offenders profit so much by living in hostels in Denmark is no sign that they would here.

To our mind the essence of the argument for or against hostels must depend on two things: whether or not thoroughly capable leaders for the groups housed together could be found; and whether or not the probationers or parolees have had their morale built up by treatment measures to the pitch that members of a group would in the main be likely to have a good influence upon each other.

Another question: could we ever in this country, say in a given state, induce enough citizens to serve actively in the capacity of advisors and friends to parolees so that they might be called upon to anything like the same extent as are the Borstal Associates, an offshoot of the Borstal Association which is the parole agency for the whole system? Scattered over England are some thousand of these volunteer associates, known for their good standing in their communities, who are ready and willing to work with the parole agents to suggest leisure-time activities and to provide social contacts for parolees, as well as to aid sometimes in finding employment for them. In connection with this, it should be stated that the head of the Borstal Association and a parole agent take pains to become rather well acquainted with the 
offender and to know his requirements and possibilities while he is still an inmate of a Borstal. This information is passed along to the Associate, for whom then the parolee is not an unknown quantity. Judge Carroll $C$. Hincks of the federal district court in Connecticut, who has been trying out on a small scale this plan of finding a friend, besides the parole officer, for parolees, holds the opinion that the idea of inducing a considerable body of citizens to serve in such a capacity might well prove to be entirely practicable.

\section{Prognosis}

Prognosis of what and for what? Prediction of parole success of an offender who has been in an American penitentiary, according to the Burgess formula?' Prediction of what the future conduct of a given offender, say, before the court is likely to be, according to the statistically computed formulations of the Gluecks? ${ }^{\circ}$ Or prediction of an offender's response to an intelligently conceived program of treatment?

We are convinced that prediction tables with regard to the future behavior of offenders, save for abnormal personalities, may receive many upsets if really good methods of treatment are established. If not, then prognoses based upon previous records of misconduct, etc., may hold true, except as they may stress good behavior in prison, for we know that some of the slickest young criminals have sense enough to know that demerits count against early parole.

The really big issue for prognosis is, first, whether the more immediate causal factors within or without the offender that have tended to make him offend have been diagnosed, and, second, whether these factors can be offset or mitigated by the forms of punishment or of training and treatment that are given him under any given system in vogue for dealing with offenders.

Prognosis, then, as in medicine, depends not only on the nature of the malady and the constitution of the individual, but also upon the expectancy of remedies that can be given him, and in some cases upon his will to recover. For the youthful offender prognosis in any instance depends upon what is done to him and for him; whether diagnostically based training and treatment is afforded him-on probation, in an institution, or on parole. The nature of the therapeutic measures offered and the offender's response to them may very well count most for the prognosis.

\footnotetext{
'See Bruce, Harno, Burgess and Landesco, Workings of the Indeterminate-Sentence Latw and the Parole System in Illinois (1928) c. XXX.

-See Sheldon and Eleanor T. Glueck, Predictability in Criminal Justice (1929) 42 HARv. L. Rzv. 300.
} 